\title{
Utilização da Farinha Pré-gelatinizada de Milho na Alimentação de Leitões na Fase de Creche. Digestibilidade e Desempenho
}

\author{
Ivan Moreira1, Gisele Cristina de Oliveira², Antônio Cláudio Furlan¹, Valquiria Mayumi Ishida \\ Patricio $^{2}$, Maurício Marcos Junior ${ }^{2}$
}

\begin{abstract}
RESUMO - Foram realizados dois experimentos, um de digestibilidade (Experimento I) e outro de desempenho (Experimento II). No experimento de digestibilidade, foram utilizados 16 leitões mestiços, machos castrados, desmamados aos 21 dias de idade e com 6,0kg de peso vivo inicial médio, alojados em gaiolas de metabolismo, contendo dois animais por unidade experimental. $\mathrm{O}$ alimento estudado foi a farinha pré-gelatinizada de milho (FPGM). Os coeficientes de digestibilidade CD da matéria seca, da proteína bruta e da energia bruta foram, respectivamente, de 89,$2 ; 78,7$ e $90,2 \%$. Os teores de matéria seca digestível, proteína digestível, energia digestível e absorção de água foram, respectivamente, de $81,8 \% ; 6,5 \% ; 3682 \mathrm{kcal} / \mathrm{kg}$ e 500\%. No experimento de desempenho, foram utilizados 96 leitões mestiços, sendo metade machos castrados e metade fêmeas, desmamados aos 21 dias de idade, em um delineamento em blocos casualizados, com quatro tratamentos, seis repetições e quatro leitões por unidade experimental, conduzido para verificar os efeitos de níveis crescentes de substituição $(0 ; 33 ; 66 ; 100 \%)$ do milho comum pela FPGM sobre o desempenho de leitões na fase de creche (21-63 dias de idade). Concluiu-se que a FPGM substituiu o milho comum até o nível de 23,7\% em rações fareladas, compostas de milho, farelo de soja e núcleo comercial, para leitões na fase de 21 a 63 dias de idade.
\end{abstract}

Palavras-chave: desempenho, digestibilidade, farinha pré-gelatinizada de milho, leitões, milho

\section{Utilization of Pre-Gelatinized Corn Meal on Nursery Phase Piglet Feeding. Digestibility and Performance}

\begin{abstract}
Two trials were carried out, Trial I (digestibility) and Trial II (performance). In Trial I, 16 castrated male crossbreed piglets were used. They were weaned at 21 days and weighing on average of $6.0 \mathrm{~kg}$. Two piglets were kept in each metabolic cage. Studding pre-gelatinized corn meal (PGCM), we found these results: digestibility coefficient of dry matter, crude protein and crude energy was 89.2, 78.7 and $90.2 \%$, respectively. Digestible dry matter ( $81.8 \%$ as-fed basis); digestible protein (6.55\% as-fed basis) and digestible energy ( $3682 \mathrm{kcal} / \mathrm{kg}$ as-fed basis) and the value of $500 \%$ for water absorption. In trial II, 96 crossbreed piglets were used, $1 / 2 \mathrm{males}$ and $1 / 2$ females, weaned at 21 days, in a randomized blocks design, with four treatments, six repetitions of four piglets per cage. It was carried out to verify the effects of increasing levels of replacement $(0 ; 33 ; 67 ; 100 \%)$ of yellow corn to pre-gelatinized corn meal, on the piglets performance at 21-63 days old. The PGCM substituted the yellow corn in diet with yellow corn, soybean meal and base mix. It was concluded that PGCM substituted the yellow corn up to the $23.7 \%$ in diet, with yellow corn, soybean meal and commercial base mix, to piglets at 21-63 days old.
\end{abstract}

Key Words: corn, digestibility, performance, pre-gelatinized corn meal, piglets

\section{Introdução}

Na criação de suínos, a alimentação representa por volta de 70 a $75 \%$ dos custos de produção (GIROTTO, 1993).

O milho tem sido o cereal mais usado na formulação de rações, no Brasil, por apresentar elevado nível energético, rico em amido (aproximadamente $72 \%)$, pobre em fibras $(<2 \%)$ e de alta palatabilidade. O milho combinado com o farelo de soja pode atender as exigências nutricionais nas rações de suínos, principalmente para os dois aminoácidos limitantes, a lisina e o triptofano (SEERLEY, 1991).

O amido de grão de milho é constituído por dois polímeros de glicose, a amilose (22 a $28 \%$ ) e a amilopectina (72 a $78 \%$ ), que formam um complexo altamente organizado, o que dificulta a ação das amilases (LAWRENCE, 1985). Essas enzimas pancreáticas e intestinais têm apresentado baixa atividade em leitões jovens (KIDDER e MANNERS, 1978). Os leitões desmamados com três semanas de idade, dependendo da condição, não possuem o sistema digestivo apto a digerir todos os nutrientes encontrados

\footnotetext{
${ }^{1}$ Professor da Universidade Estadual de Maringá - DZO, Maringá - PR. E.mail: imoreira@uem.br

2 Alunos do curso de Zootecnia/UEM e bolsistas, respectivamente, do PET/CAPES/UEM, PIBIC/CNPq e de IC/CNPq.
} 
nos alimentos tradicionais, o que comprometer-lhes a digestibilidade. Assim, torna-se necessário estudar dietas que possuam ingredientes altamente digestíveis durante o período pós-desmame, visando minimizar os problemas de digestão e má absorção no intestino dos leitões e maximizar o desempenho.

Para que os leitões jovens possam ter o melhor aproveitamento possível do milho, estão sendo conduzidos estudos na área de processamento de amido, como extrusão, micronização, cozimento, entre outros, objetivando a "desorganização" da estrutura do grânulo de amido, para facilitar a ação da enzima amilase no processo de digestão e absorção. O milho, quando processado adequadamente por calor, possui melhor digestibilidade dos seus nutrientes, principalmente da energia (LAWRENCE, 1973, 1975).

Utilizando-se o método de extrusão, têm-se obtido amidos modificados com maiores valores de solubilidade em água e com alta capacidade de absorver água, em virtude da gelatinização e dextrinização (GROSSMANN et al., 1988). Esses amidos modificados têm permitido aos leitões melhor digestão e absorção dos nutrientes, melhorando assim a eficiência de utilização das rações, bem como o desempenho dos animais (MOREIRA, 1993).

São escassas as bibliografias relativas à digestibilidade dos nutrientes e à utilização de milho processado a calor na alimentação de leitões, assim, são necessárias mais pesquisa sobre esse assunto.

No presente trabalho objetivou-se determinar os coeficientes de digestibilidade dos nutrientes e do valor energético da farinha pré-gelatinizada de milho e o estudo dos efeitos da inclusão da mesma em substituição ao milho comum em rações práticas, na fase de creche, sobre o desempenho de leitões desmamados aos 21 dias de idade.

\section{Material e Métodos}

Foram realizados dois experimentos, um de digestibilidade (Experimento I) e outro de desempenho (Experimento II), com leitões desmamados aos 21 dias de idade.

O alimento estudado foi a farinha pré-gelatinizada de milho, a qual foi obtida a partir de grãos sadios de milho (Zea mays L.) degerminado, moído e submetido às operações de pré-gelatinização por extrusão e posteriormente seco, moído e classificado. De acordo com o fabricante, a retenção máxima em peneiras ABNT-40 é de 20\%, o que representa $80 \%$ de partículas menores que $0,42 \mathrm{~mm}$ e com características organolépticas marcantes, tendo aspecto de um produto fino, uniforme, cor amarela característico, sabor e aroma suave característico do milho.

Experimento I (ensaio de digestibilidade)

O experimento foi conduzido na sala de metabolismo do setor de suinocultura, da Fazenda Experimental de Iguatemi (FEI), da Universidade Estadual de Maringá (UEM).

Foram utilizados 16 leitões machos castrados, desmamados aos 21 dias de idade, com média de $6,0 \mathrm{~kg}$ de peso vivo. Os leitões, logo após o desmame, foram transferidos para gaiolas de metabolismo do "tipo Pekas", as quais abrigaram dois leitões/gaiola, o que representou a unidade experimental. $\mathrm{O}$ experimento consistiu em um período de cinco dias de adaptação às gaiolas e às rações, seguidos de cinco dias de coleta de fezes e urina.

Foi formulada uma ração referência (RR) à base de milho, farelo de soja e núcleo, cuja composição centesimal se encontra na Tabela 1 . A ração teste (RT) foi composta de $70 \%$ da RR e $30 \%$ de farinha pré-gelatinizada de milho (alimento teste). A ração referência (Tabela 1) foi formulada para atender as exigências nutricionais de leitões com aproximadamente $6 \mathrm{~kg}$ de peso vivo, segundo o NATIONAL RESEARCH COUNCIL - NRC (1998).

Os leitões receberam quatro refeições diárias, fornecidas às 7, 10, 13h30 e 16h30, nas proporções de $38 ; 19 ; 19$ e $24 \%$ da quantidade total, respectivamente. A quantidade total diária foi definida de acordo com o consumo na fase de adaptação, baseado no peso metabólico $\left(\mathrm{kg}^{0,75}\right)$ de cada unidade experimental. As rações foram umedecidas com $15 \%$ de água, para evitar desperdício, reduzir a pulverulência e facilitaro

Tabela 1 - Composição centesimal da ração referência (Experimento I)

Table 1 - Percentage composition of basal diet (Trial I)

\begin{tabular}{ll}
\hline $\begin{array}{l}\text { Ingredientes } \\
\text { Feeds }\end{array}$ & $\%$ \\
\hline Milho comum & 37 \\
Yellow corn & \\
Farelo de soja & 23 \\
$\begin{array}{l}\text { Soybean meal } \\
\text { Núcleo } 1\end{array}$ & 40 \\
Commercial base mix & \\
\hline
\end{tabular}

${ }_{1}$ Núcleo contendo calcário calcítico, fosfato bicálcico, soro de leite em pó, açúcar, cloreto de sódio, premix vitamínico-mineral aminoácido, flavorizante e aditivo acidulante.

1 Commercial base mix contained limestone, dicalcium phosphate, whey of powdered milk, sucrose, salt, vitamin-mineral premix, flavored and acidulated. 
442 Rev. bras. zootec.

consumo. Após cada refeição, foi oferecida água no mesmo comedouro, à base de $3,0 \mathrm{~mL} / \mathrm{g}$ de ração.

Foram usados o indicador $\mathrm{Cr}_{2} \mathrm{O}_{3}(0,5 \%$ de inclusão) e o marcador $\mathrm{Fe}_{2} \mathrm{O}_{3}$ (2\% de inclusão).

A urina foi coletada uma vez por dia em baldes plásticos com $20 \mathrm{~mL}$ de HCI 1:1, com objetivo de não permitir a perda do nitrogênio e a proliferação de bactérias. Foi colocado sob o funil coletor um tecido conhecido como "filó", visando reter possíveis resíduos fecais. A coleta foi realizada às $7 \mathrm{~h} 30$, sendo que o líquido do balde foi completado para volumes fixos para facilitar a retirada de alíquota de $20 \%$. A urina foi armazenada em frascos no congelador, para análises laboratoriais, que foram realizadas no Laboratório de Nutrição Animal do Departamento de Zootecnia da Universidade Estadual de Maringá (LANA/DZO/ DEM), de acordo com MARA (1992).

$O$ índice de controle de qualidade do processamento usado foi a absorção de água, de acordo com a técnica proposta por HOLAY e HARPER (1982). Foram pesados 40 gramas da amostra, colocadas em béquer de $500 \mathrm{~mL}$, adicionados $200 \mathrm{~mL}$ de água quente $\left(60^{\circ} \mathrm{C}\right)$, seguindo-se de agitação por 10 segundos. Após, foi deixada a amostra embeber por três minutos e, depois, filtrada por $1 / 2$ minuto, em papel-filtro. O volume filtrado (V), que representa a água não absorvida, foi anotado e utilizado para o cálculo, segundo a equação (Absorção de água $(\%)=[(200-\mathrm{V}) / 40] * 100)$.

Foram calculados os coeficientes de digestibilidade da matéria seca (CDMS), coeficiente de digestibilidade da proteína bruta (CDPB) e coeficiente de digestibilidade de energia bruta (CDEB) do alimento, determinado pelo método de coleta total e do indicador óxido crômico, conforme MOREIRA et al. (1994). Foi aplicada a fórmula de MATTERSON et al. (1965) para a obtenção dos valores energéticos da FPGM.

\section{Experimento II (ensaio de desempenho)}

$\mathrm{O}$ experimento de desempenho foi conduzido no setor de suinocultura, da Fazenda Experimental de Iguatemi (FEI) da Universidade Estadual de Maringá (UEM).

Foram utilizados 96 leitões mestiços (sendo metade machos castrados e metade fêmeas), desmamados aos 21 dias de idade, que entraram no experimento com 21 dias e saíram com 63 dias. Os leitões desmamados foram transferidos para as creches suspensas e distribuídos em um delineamento experimental em blocos casualizados, com quatro tratamentos, seis repetições e quatro leitões por unidade experimental. Os tratamentos consistiram de quatro rações, cuja composição se encontra nas Tabelas 2, 3 e 4, formuladas à base de milho, farelo de soja e núcleo comercial, atendendo as exigências nutricionais de acordo com NRC (1998) de leitões nas respectivas faixas etárias.

Os leitões foram pesados no início e ao final de cada fase de troca de ração $(31,45$ e 63 dias de idade). As rações foram fornecidas na forma farelada e à vontade. As sobras foram pesadas e anotadas ao final de cada fase, visando obter a média de consumo por fase.

As variáveis ganho de peso diário (GPD), consumo de ração $(\mathrm{CO})$ e conversão alimentar (CA) foram submetidas às análises de variância e regressão polinomial, utilizando o seguinte modelo estatístico:

Tabela 2 - Composição centesimal das rações experimentais (Fase I: 21-31 dias de idade) [Experimento II] Table 2 - Percentage composition of experimental diets (Phase I: 21 - 31 days old) [Trial II]

\begin{tabular}{|c|c|c|c|c|}
\hline \multirow[b]{2}{*}{$\begin{array}{l}\text { Ingredientes } \\
\text { Feed }\end{array}$} & \multicolumn{4}{|c|}{$\begin{array}{l}\text { Níveis de substituição, \% } \\
\text { Replacement level, \% }\end{array}$} \\
\hline & 0 & 33 & 67 & 100 \\
\hline $\begin{array}{l}\text { Milho comum, } \mathrm{kg} \\
\text { Yellow corn, } \mathrm{kg}\end{array}$ & 37,00 & 24,67 & 12,33 & - \\
\hline $\begin{array}{l}\text { Farinha pré-gelatinizada de milho, } \mathrm{kg} \\
\text { Pre-gelatinized corn meal, } \mathrm{kg}\end{array}$ & - & 12,33 & 24,67 & 37,00 \\
\hline $\begin{array}{l}\text { Farelo de soja, } \mathrm{kg} \\
\text { Soybean meal, } \mathrm{kg}\end{array}$ & 23,00 & 23,00 & 23,00 & 23,00 \\
\hline $\begin{array}{l}\text { Núcleo }^{1}, \mathrm{~kg} \\
\text { Commercial base mix, } \mathrm{kg}^{\text {Commen }}\end{array}$ & 40,00 & 40,00 & 40,00 & 40,00 \\
\hline
\end{tabular}

\footnotetext{
${ }^{1}$ Núcleo contendo calcário calcítico, fosfato bicálcico, soro de leite em pó, açúcar, cloreto de sódio, premix vitamínico-mineral, aminoácido, flavorizante, e aditivo acidulante.

1 Commercial base mix contained limestone, dicalcium phosphate, whey of powdered milk, sucrose, salt, vitamin-mineral premix, flavored and acidulated.
} 
Tabela 3 - Composição centesimal das rações experimentais (Fase II: 32-45 dias de idade) [Experimento II] Table 3 - Percentage composition of experimental diets (Phase II: 32 - 45 days old)[Trial II]

\begin{tabular}{|c|c|c|c|c|}
\hline \multirow[b]{2}{*}{$\begin{array}{l}\text { Ingredientes } \\
\text { Feed }\end{array}$} & \multicolumn{4}{|c|}{$\begin{array}{l}\text { Níveis de substituição, \% } \\
\text { Replacement level, \% }\end{array}$} \\
\hline & 0 & 33 & 66 & 100 \\
\hline $\begin{array}{l}\text { Milho comum, } \mathrm{kg} \\
\text { Yellow corn, } \mathrm{kg}\end{array}$ & 55,00 & 36,67 & 18,33 & - \\
\hline $\begin{array}{l}\text { Farinha pré-gelatinizada de milho, } \mathrm{kg} \\
\text { Pre-gelatinized corn meal, } \mathrm{kg}\end{array}$ & - & 18,33 & 36,67 & 55,00 \\
\hline $\begin{array}{l}\text { Farelo de soja, } \mathrm{kg} \\
\text { Soybean meal, } \mathrm{kg}\end{array}$ & 30,00 & 30,00 & 30,00 & 30,00 \\
\hline $\begin{array}{l}\text { Núcleo }^{1}, \mathrm{~kg} \\
\text { Commercial base mix, } \mathrm{kg}\end{array}$ & 15,00 & 15,00 & 15,00 & 15,00 \\
\hline
\end{tabular}

Tabela 4 - Composição centesimal das rações experimentais (Fase inicial: 46-63 dias de idade) [Experimento II] Table 4 - Percentage composition of the experimental diets (Initial phase: 46 - 63 days old) [Trial II]

\begin{tabular}{|c|c|c|c|c|}
\hline \multirow[b]{2}{*}{$\begin{array}{l}\text { Ingredientes } \\
\text { Feed }\end{array}$} & \multicolumn{4}{|c|}{$\begin{array}{l}\text { Níveis de substituição, \% } \\
\text { Replacement level, \% }\end{array}$} \\
\hline & 0 & 33 & 66 & 100 \\
\hline $\begin{array}{l}\text { Milho comum, } \mathrm{kg} \\
\text { Yellow corn, } \mathrm{kg}\end{array}$ & 66,00 & 44,00 & 22,00 & - \\
\hline $\begin{array}{l}\text { Farinha pré-gelatinizada de milho, } \mathrm{kg} \\
\text { Pre-gelatinized corn meal, } \mathrm{kg}\end{array}$ & - & 22,00 & 44,00 & 66,00 \\
\hline $\begin{array}{l}\text { Farelo de soja, } \mathrm{kg} \\
\text { Soybean meal, } \mathrm{kg}\end{array}$ & 30,00 & 30,00 & 30,00 & 30,00 \\
\hline $\begin{array}{l}\text { Núcleo }^{1}, \mathrm{~kg} \\
\text { Commercial base mix, } \mathrm{kg}\end{array}$ & 4,00 & 4,00 & 4,00 & 4,00 \\
\hline
\end{tabular}

${ }^{1}$ Núcleo contendo calcário calcítico, fosfato bicálcico, cloreto de sódio, premix vitamínico-mineral e aminoácido.

${ }^{1}$ Commercial base mix contained limestone, salt and vitamin-mineral premix.

$$
\mathrm{Y}_{i j k}=\mathrm{M}+\mathrm{N}_{i}+\mathrm{B}_{j}+\mathrm{e}_{i j k}
$$

em que $\mathrm{Y}_{i j k}$ refere-se a variáveis observadas; $\mathrm{M}$, média geral; $\mathrm{N}_{i}$, efeito dos níveis de substituição do milho comum pela FPGM $i(i=0 ; 33 ; 67 ; 100 \%)$; $\mathrm{B}_{j}$, efeito de bloco $j(j=1,2 \ldots 6) ; \mathrm{E}_{i j k}$, erro aleatório associado à cada observação.

Para a determinação do nível ótimo de substituição do milho comum pela FPGM, foi utilizado o modelo quadrático.

\section{Resultados e Discussão}

\section{Experimento I (ensaio de digestibilidade)}

Os resultados obtidos quanto aos teores de matéria seca (MS), proteína bruta $(\mathrm{PB})$, energia bruta
$(\mathrm{EB})$, cálcio $(\mathrm{Ca})$, fósforo total $(\mathrm{Pt})$ e extrato etéreo (EE), da (FPGM), em comparação ao milho comum (MC), encontram-se na Tabela 6.

O valor médio de absorção de água do FPGM foi de 500\%. Segundo LAWRENCE (1985), com o processamento do milho, o grânulo pode ser aquecido, absorver água e se expandir, exudando a parte da amilose, ocorrendo a ruptura das ligações secundárias de hidrogênio que prendem a cadeia do polímero, perdendo, com isso, a berrifrigência e tornando-se mais suscetível à degradação enzimática. Essa ruptura, denominada gelatinização, pode estar associada ao processo de absorção de água. Com base nestes conceitos, este resultado de absorção de água evidencia o eficiente grau de gelatinização da FPGM 
444 Rev. bras. zootec.

Tabela 5 - Teores de matéria seca (MS), proteína bruta $(\mathrm{PB})$, cálcio $(\mathrm{Ca})$ e fósforo total $(\mathrm{Pt})$, das rações experimentais das diferentes fases [Experimento II]

Table 5 - Values of dry matter (DM), crude protein (CP), calcium (Ca) and total phosphorus, of the experimental diets of the different studied phases [Trial II]

\begin{tabular}{|c|c|c|c|c|}
\hline \multirow[t]{2}{*}{$\begin{array}{l}\text { Nutrientes } \\
\text { Nutrients }\end{array}$} & \multicolumn{4}{|c|}{$\begin{array}{c}\text { Níveis de substituição do MC pela FPGM, \% } \\
\text { Replacement level of YC for PGCM, \% }\end{array}$} \\
\hline & 0 & 33 & 66 & 100 \\
\hline \multicolumn{5}{|c|}{$\begin{array}{l}\text { Fase I (21-31 dias de idade) } \\
\text { Phase I (21-31 days old })\end{array}$} \\
\hline $\begin{array}{l}\text { Matéria seca, \% } \\
\text { Dry matter }\end{array}$ & 90,81 & 90,64 & 90,83 & 91,09 \\
\hline $\begin{array}{l}\text { Proteína bruta, \% } \\
\text { Crude protein }\end{array}$ & 18,97 & 18,98 & 19,55 & 20,89 \\
\hline $\begin{array}{l}\text { Cálcio, \% } \\
\text { Calcium }\end{array}$ & 0,79 & 0,82 & 0,86 & 0,74 \\
\hline $\begin{array}{l}\text { Fósforo total, \% } \\
\text { Total phosphorus }\end{array}$ & 0,69 & 0,63 & 0,82 & 0,81 \\
\hline \multicolumn{5}{|c|}{$\begin{array}{l}\text { Fase II ( } 32-45 \text { dias de idade) } \\
\text { Phase II ( } 32-45 \text { days old })\end{array}$} \\
\hline $\begin{array}{l}\text { Matéria seca, } \% \\
\text { Dry matter }\end{array}$ & 90,39 & 90,77 & 91,19 & 91,43 \\
\hline $\begin{array}{l}\text { Cálcio, \% } \\
\text { Calcium }\end{array}$ & 0,75 & 0,74 & 0,82 & 0,80 \\
\hline $\begin{array}{l}\text { Fósforo total, } \% \\
\text { Total phosphorus }\end{array}$ & 0,74 & 0,82 & 0,89 & 0,72 \\
\hline \multicolumn{5}{|c|}{$\begin{array}{l}\text { Fase inicial ( } 46-63 \text { dias de idade) } \\
\text { Initial phase ( } 46-63 \text { days old) }\end{array}$} \\
\hline $\begin{array}{l}\text { Matéria seca, } \% \\
\text { Dry matter }\end{array}$ & 90,01 & 90,47 & 91,18 & 92,06 \\
\hline $\begin{array}{l}\text { Proteína bruta, \% } \\
\text { Crude protein }\end{array}$ & 18,78 & 18,79 & 18,87 & 19,25 \\
\hline $\begin{array}{l}\text { Cálcio, \% } \\
\text { Calcium }\end{array}$ & 1,07 & 0,98 & 1,02 & 0,96 \\
\hline $\begin{array}{l}\text { Fósforo total, \% } \\
\text { Total phosphorus }\end{array}$ & 0,72 & 0,63 & 0,75 & 0,63 \\
\hline
\end{tabular}

Análises feitas no laboratório de Nutrição Animal-DZO/UEM (LANA/DZO/UEM).

Analyses determined at Animal Nutrition Laboratory-DZO/UEM (LANA/DZO/UEM).

Tabela 6 - Teores de matéria seca (MS), proteína bruta (PB), energia bruta $(E B)$, cálcio $(\mathrm{Ca})$, fósforo total (Pt) e extrato etéreo (EE), da farinha pré-gelatinizada de milho (FPGM) e do milho comum (MC) [Experimento I]

Table 6 - Values of dry matter (DM), crude protein (CP), gross energy (GE), calcium (Ca), total phosphorus (TP) and ether extract (EE), of the pre-gelatinized corn meal (PGCM) and of the yellow corn (CC) [Trial I]

\begin{tabular}{|c|c|c|c|c|c|c|}
\hline Alimento & $\operatorname{MS}(\%)$ & $\mathrm{PB}(\%)$ & $\mathrm{EB}(\mathrm{kcal} / \mathrm{kg})$ & $\mathrm{Ca}(\%)$ & $\operatorname{Pt}(\%)$ & $\mathrm{EE}(\%)$ \\
\hline Feed & $D M(\%)$ & $C P(\%)$ & $G E(\mathrm{kcal} / \mathrm{kg})$ & $\mathrm{Ca}(\%)$ & $T P(\%)$ & $E E(\%)$ \\
\hline FPGM $^{1}$ & 91,72 & 8,17 & 4080 & 0,01 & 0,22 & 1,99 \\
\hline $\mathrm{MC}^{2}$ & 87,45 & 8,68 & 3950 & 0,04 & 0,26 & 3,84 \\
\hline
\end{tabular}

${ }_{1}^{1}$ Análises feitas no Laboratório de Nutrição Animal - DZO/UEM (LANA/DZO/UEM).

2 EMBRAPA (1991).

1 Analyses determined at Animal Nutrition Laboratory - DZO/UEM (LANA/DZO/UEM).

2 EMBRAPA(1991). 
utilizado, visto que apresentou valor máximo de absorção de água. Estes resultados foram semelhantes aos obtidos por MOREIRA et al. (1994), quando trabalharam com FPGM semelhante à esta.

Os coeficientes de digestibilidade do alimento determinados pelo método de coleta total e pelo óxido crômico estão na Tabela 7.

Não houve diferença $(\mathrm{P}>0,05)$ entre os coeficientes de digestibilidade determinados pelo método de coleta total ou pelo indicador óxido crômico, o que indica que ambos podem ser utilizados para a definição dos coeficientes de digestibilidade da FPGM.

O processamento que resultou na FPGM apresentou o mesmo CDPB encontrado por MOREIRA et al. (1994), porém o CDEB encontrado foi $2,7 \%$ inferior.

MOREIRA et al. (1994) obtiveram valores para milho comum de 83,$71 ; 47,55$ e $80,60 \%$ para CDMS, CDPB e CDEB, respectivamente. Comparando os coeficientes de digestibilidade encontrados para a FPGM no presente trabalho com os obtidos por MOREIRA et al. (1994), verificou-se maior valor de digestibilidade para FPGM usada neste estudo.

Os resultados dos nutrientes digestíveis e valores energéticos estão na Tabela 8.

HERKELMAN et al. (1990) e MOREIRA et al. (1994) obtiveram valores de ED do milho comum menor que do milho processado, sendo que o valor de ED da FPGM obtido e divulgado no presente trabalho

Tabela 7 - Coeficientes de digestibilidade dos nutrientes (CDMS-matéria seca; CDPB-proteína bruta; CDEB-energia bruta), determinados pelo métodos de coleta total e de indicador óxido crômico [Experimento I]

Table 7 - Digestibility coefficients of the nutrients (DCDM-dry matter; DCCP-crude protein; DCGE-gross energy), obtained by total collection and by the indicator $\mathrm{Cr}_{2} \mathrm{O}_{3}$ methods [Trial I]

\begin{tabular}{|c|c|c|c|}
\hline Métodos & CDMS (\%) & $\mathrm{CDPB}(\%)$ & $\operatorname{CDEB}(\%)$ \\
\hline Methods & $D C D M(\%)$ & $\operatorname{DCCP}(\%)$ & DCGE (\%) \\
\hline Coleta total & $89,46^{\mathrm{a}}$ & $80,43^{a}$ & $90,51^{\mathrm{a}}$ \\
\hline Total collection & & & \\
\hline $\begin{array}{l}\text { Indicador } \mathrm{Cr}_{2} \mathrm{O}_{3} \\
\text { Indicator } \mathrm{Cr}_{2} \mathrm{O}_{3}\end{array}$ & $88,87^{\mathrm{a}}$ & $78,93^{\mathrm{a}}$ & $89,96^{\mathrm{a}}$ \\
\hline Média & 89,20 & 79,70 & 90,20 \\
\hline $\begin{array}{l}\text { Average } \\
\mathrm{CV}(\%)\end{array}$ & 1,65 & 9,04 & 1,64 \\
\hline \multicolumn{4}{|c|}{$\begin{array}{l}\text { Médias seguidas de letras diferentes na mesma coluna, diferem, pelo } \\
\text { Teste } F(P>0,05) \text {. } \\
\text { CV - Coeficiente de variação. } \\
\text { Means, within a colunm, followed by different letters are different by } F \text { test } \\
(P>.05) \text {. } \\
C V \text { - Coefficient of variation. }\end{array}$} \\
\hline
\end{tabular}

(3682 kcal de ED/kg) foi cerca de $5 \%$ superior ao obtido (3512 kcal de ED/kg) por MOREIRA et al. (1994) e muito próximo ao obtido (3665 kcal de ED/kg) por VIOLA et al. (1996). Este resultado pode ser explicado pelo fato de a FPGM apresentar maior nível de gordura, ou mesmo diferente parâmetro de processamento, em relação àquela estudada por MOREIRA et al. (1994).

\section{Experimento II (ensaio de desempenho)}

Os resultados obtidos para consumo diário de ração (CDR), ganho diário de peso (GDP) e conversão alimentar (CA) encontram-se na Tabela 9.

Na fase I (21-31 dias de idade), houve efeito quadrático da inclusão de FGPM sobre o GDP. Pode-se inferir, por intermédio da derivação da equação quadrática (Tabela 9), que o maior GDP ocorreu no nível de 52,2\% de substituição.

A partir das análises dos dados de desempenho (Tabela 9), no período total (21-63 dias de idade), verificou-se efeito quadrático dos níveis de substituição do milho comum pela FPGM sobre o CDR (Figura 1) e GDP (Figura 2). Observou-se ainda aumento linear da CA, com a elevação dos níveis de FPGM.

Com a derivação das equações quadráticas (Tabela 9), obteve-se nível 23,7\% de inclusão para GDP (Figura 1) e de 38, $81 \%$ para CDR (Figura 2).

Provavelmente, a textura do FPGM (partículas menores que $0,42 \mathrm{~mm}$ ) tenha sido a responsável pela redução de consumo, com o aumento da inclusão da FGPM na ração, pois constatou-se que a ração aderiu à boca do leitão, formando uma placa pegajosa, que foi expelida. Como não foi possível esse tipo de perda, é provável que esta tenha sido a responsável pelo aumento da $\mathrm{CA}$, à medida que se elevou o nível de FPGM na ração.

MOREIRA (1994), BARBOSA et al. (1997) e BARBOSA et al. (1998), trabalhando com leitões desmamados aos 21 dias de vida, observaram que não houve melhora no desempenho usando milho précozido em comparação ao milho comum. Segundo esses autores, este fato se deve ao elevado desperdício de ração, em função da granulometria muito fina da FMPG.

Trabalhando com leitões desmamados aos 28 dias de idade, BERTOL et al. (1995) verificaram que o milho moído, com tamanho de partícula de $381 \mathrm{~mm}$, em dietas fareladas influenciou negativamente o desempenho de leitões pós-desmame, reduzindo o consumo de ração e piorando a conversão alimentar. Segundo esses autores, esta redução no desempenho 
446 Rev. bras. zootec.

Tabela 8 - Nutrientes digestíveis (matéria seca digestível-MSD, proteína digestível-PD e energia digestível - ED) e energia metabolizável - EM da farinha pré-gelatinizada de milho (valores na matéria natural) ${ }^{1}$ [Experimento I]

Table 8 - Digestible nutrients (digestible dry matter-DDM, digestible protein-DP and digestible energy-DE) and metabolizable energyME of the pre-gelatinized corn meal (as-fed basis) ${ }^{1}$ [Trial I]

\begin{tabular}{lcccc}
\hline Alimento & MSD $(\%)$ & PD $(\%)$ & ED $(\mathrm{kcal} / \mathrm{kg})$ & $\mathrm{EM}(\mathrm{kcal} / \mathrm{kg})$ \\
Feed & $D D M(\%)$ & $D P(\%)$ & $D E(k c a / \mathrm{kg})$ & $3 E(k c a l / \mathrm{kg})$ \\
\hline FPGM & 81,8 & 6,5 & 3682 & 3565 \\
$P G C M$ & & & & \\
\hline
\end{tabular}

Os valores foram calculados tendo como base os valores constantes nas Tabelas 6 e 7.

The results were obtained from the values in the tables 6 and 7 .

Tabela 9 - Desempenho de leitões desmamados aos 21 dias de idade, recebendo dietas com níveis crescentes da farinha pré-gelatinizada de milho (FPGM) [Experimento II]

Table 9 - Performance of piglets weaned at 21 days of age fed diets with increasing levels of pre-gelatinized corn meal (PGCM) [Trail II]

Variáveis Níveis de substituição do milho comum pela FPGM, \%

Variables

Replacement level the yellow corn for the PGCM, \%

$\begin{array}{lllll}0 & 33 & 67 & 100 & \text { Efeito }\end{array}$

Effect

$\mathrm{CV}(\%)$

Fase I (21-31 dias de idade)

Phase I (21-31 days old)

Peso inicial, $\mathrm{kg}$

Initial weight

Consumo diário de ração, $\mathrm{g}$

Daily feed intake

Ganho diário de peso, $\mathrm{g}$

Average daily gain

Conversão alimentar

Feed: gain ratio

6,07

228

64

3,54

Fase II (32-45 dias de idade)

Phase II (32-45 days old

Peso inicial, $\mathrm{kg}$

Initial weight

Consumo diário de ração, g

Daily feed intake

Ganho diário de peso, $\mathrm{g}$

Average daily gain

Conversão alimentar

Feed: gain ratio

Fase inicial (46-63 dias de idade)

Initial phase (46-63 days old)

Peso inicial, $\mathrm{kg}$

Initial weight

Consumo diário de ração, $\mathrm{g}$

Daily feed intake

Ganho diário de peso, g

Average daily gain

Conversão alimentar

Feed: gain ratio

Fase total (21-63 dias de idade)

Total phase (21-63 days old)

Peso inicial, $\mathrm{kg}$

Initial weight

Consumo diário de ração, g

Daily feed intake

Ganho diário de peso, g

Average daily gain

Conversão alimentar

Feed: gain ratio

Não-significativo $(P>0,05) ;{ }^{1} \mathrm{GDP}=0,066280312+0,001247753 \mathrm{X}-0,0000119522 \mathrm{X}^{2} ;{ }^{2} \mathrm{CDR}=0,774105634+0,001793797 \mathrm{X}-0,00002311306 \mathrm{X}^{2}$;

${ }^{3} \mathrm{GDP}=0,3820425+0,000495662 \mathrm{X}-0,00001045532 \mathrm{X}^{2} ;{ }^{4} \mathrm{CA}=1,955781725+0,001697782 \mathrm{X}$ 


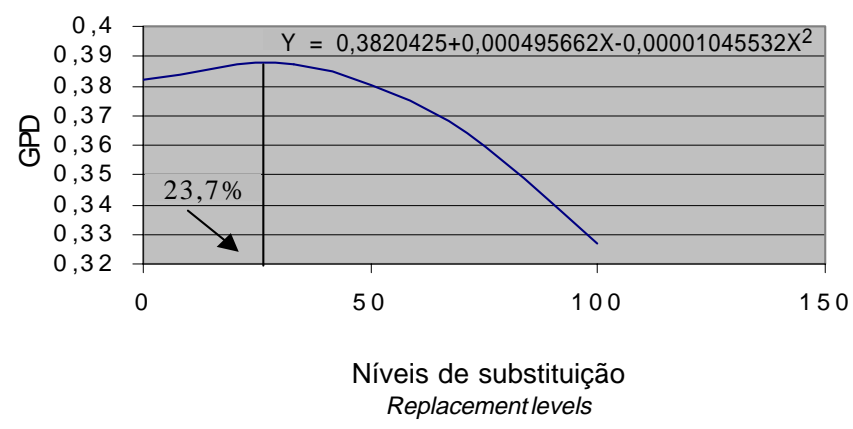

Figura 1 - Consumo diário de ração na fase total (CDR), em relação aos diferentes níveis de substituição (\%) de MC pela FPGM [Experimento II].

Figure 1 - Daily feed intake in total phase, according to different replacement level (\%) of YC for PGCM [Trial II].

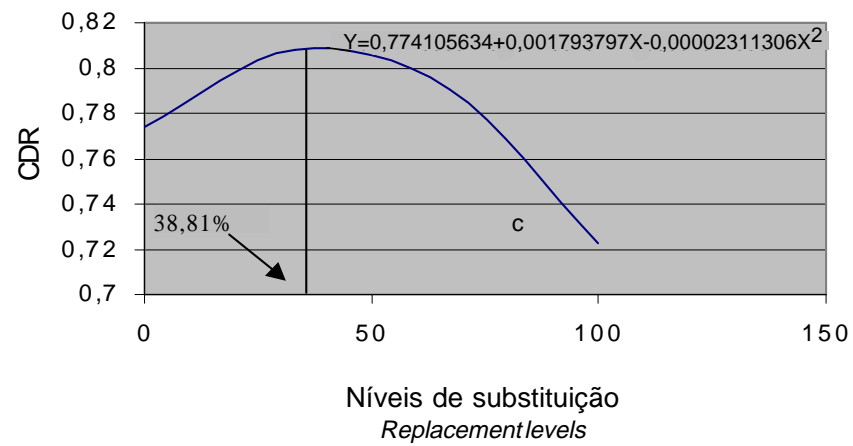

Figura 2 - Ganho diário de peso na fase total (GDP), em relação aos diferentes níveis de substituição (\%) do MC pela FPGM [Experimento II].

Figure 2 - Average daily gain in total phase, according to different replacement level (\%) of YC for PGCM [Trial II].

ocorreu em virtude da maior pulverulência, característica das rações que contêm ingredientes com granulometrias finas.

Assim, é possível inferir que os níveis de substituição de milho por FGPM devem ser definidos pelo GDP.

\section{Conclusões}

Os coeficientes de digestibilidade da farinha prégelatinizada de milho para MS, PB e EB são de 89,2; 78,7 e $90,2 \%$ e os valores de energia digestível e energia metabolizável, $3682 \mathrm{kcal}$ de $\mathrm{ED} / \mathrm{kg}$ (na MN) e $3565 \mathrm{kcal} \mathrm{de} \mathrm{EM/kg} \mathrm{(na} \mathrm{MN).}$

A farinha pré-gelatinizada de milho substitui em $52,2 \%$ o milho comum em rações fareladas, para leitões de 21 a 31 dias, e em $23,7 \%$, para leitões de 21 a 63 dias de idade, sem prejuízos do desempenho de leitões.

\section{Agradecimento}

À KOWALSKI Alimentos S/A, pela doação do produto PREGEL 404® e pelo financiamento parcial da pesquisa.

\section{Referências Bibliográficas}

BARBOSA, H.P., TRINDADE NETO, M.A., SORDI, I.M.P. et al. Milho comum e soja integral processados - Efeitos no desempenho de leitões desmamados aos 28 dias de idade. In: REUNIÃO ANUAL DA SOCIEDADE BRASILEIRA DE ZOOTECNIA, 35, 1998, Botucatu. Anais... Viçosa: SBZ, 1998. p.210-220.

BARBOSA, H.P., TRINDADE NETO, M.A., SORDI, I.M.P et al. Efeitos do processamento do milho comum e da soja integral processados no desempenho de leitões desmamados aos 21 dias de idade. In: REUNIÃO ANUAL DA SOCIEDADE BRASILEIRA DE ZOOTECNIA, 34, 1997, Juiz de Fora. Anais... Juiz de Fora: SBZ, 1997. p.124-126.

BERTOL, T.M., BRITO, B.G. Efeito do grau de moagem do milho sobre o desempenho de leitões na fase de creche. In: CONGRESSO BRASILEIRO DE VETERINÁRIOS ESPECIALISTA EM SUÍNOS, 7, 1995, Blumenau. Anais.. Blumenau: ABRAVES, 1995. p.167.

EMBRAPA. CNPSA. 1991. Tabela de composição química e valores energéticos de alimentos para suínos e aves. 3.ed. Concórdia: 97p. (EMBRAPA-CNPSA. Documento, 19).

GIROTTO, A.F. 1993. Custo médio de produção de suínos para abate: Embrapa Suínos e Aves. 2p. (Embrapa Suínos e Aves. Comunicado Técnico, 206).

GROSSMANN, M.V.E., EL-DASH, A.A., CARVALHO, J.F., 1988.Extrusion cooking effects on hydratrion properties of manioc starch. Arg. Biol. Tecnol., 31:329-335.

HERKELMAN, K.L., RODHOUSE, S.L., VEUM, T.L. et al. 1990. Effect of extrusion on ileal and fecal digestibilities of lyzine in yellow corn in diets for young pigs. J. Anim. Sci., 68:2814-2824.

HOLAY, S.H., HARPER, J.M. 1982. Influence of the extrusion shear environment on plant protein texturization. J. Food Sci., 47(6):1869-1874.

KIDDER, D.E., MANNERS, M.J. 1978. Digestion in the pig. London: Scien. Bristol. 201p.

LAWRENCE, T.L.J. 1973. An evaluation of the micronization process for preparing cereals for the growing pig. 2. Effects on growth rate, food conversion efeciency and carcass characteristics. Anim. Prod., 16:99-107.

LAWRENCE, T.L.J. 1975. An evaluation of the micronization process for preparing cereals for the growing pig. 3. A note on the effect of micronization temperature on the nutritive value of wheat. Anim. Prod., 20:167-170.

LAWRENCE, T.L.J. 1985. Processing and preparation of cereals for pig diets. In: COLE, D.J.A., HARESIGN, W. (Eds.) Recent developments in pig nutrition. London: Butterworths. p.230-45.

MARA. 1992. Métodos analíticos de controle de alimentos para uso animal. São Paulo: ANFAR. 208p.

MATTERSON, L.D., POTTER, S.N., STUTZ, M.W. et al. 1965. The metabolizable energy of feed ingredients for chikens. Storrs, Connecticut: University of Connecticut, Agricultural Experiment Station. 11p. (Research Report, 7). 
448 Rev. bras. zootec.

MOREIRA, I., ROSTAGNO, H.S., COELHO, D.T. et al. 1994. Determinação dos coeficientes de digestibilidade, valores energéticos e índices de controle de qualidade do milho e soja integral processados a calor. R. Soc. Bras. Zootec., 23:916-929.

MOREIRA, I. Valor nutritivo e utilização de milho e soja integral processados a calor na alimentação de leitões. Viçosa, MG: UFV, 1993. 145p. Tese (Doutorado em Zootecnia). Universidade Federal de Viçosa, 1993.

NATIONAL RESEARCH COUNCIL - NRC. 1998. Nutrient requirement of swine. 10.ed.Washington, D.C.: National Academic of Sciences. 189p.

SEERLEY, R.W. 1991. Major feedstuffs used in swine diets. In: MILLER, E.R., ULLREY, D.E., LEWIS, A.J. (Eds.) Swine nutrition. London, Butterworth-Heinemann. p.451-81.
VIOLA, E.S., BARTLES, H.A.S., LUDKE, J.V. et al. Digestibilidade de subprodutos do beneficiamento de arroz e do milho pré-cozido para suínos. In: REUNIÃO ANUAL DA SOCIEDADE BRASILEIRA DE ZOOTECNIA, 33, 1996, Fortaleza. Anais... Fortaleza: SBZ, 1996. p.243-245.

Recebido em: 03/05/00

Aceito em: 09/11/00 